\title{
Desafios e Missão do Intelectual Público
}

\author{
Marco Aurélio Nogueira
}

Em homenagem a Carlos Estevam Martins (1934-2009)

\begin{abstract}
A morte do cientista social Carlos Estevam Martins, aos 74 anos, ocorrida em outubro de 2009, privou a intelectualidade brasileira de uma de suas aves raras.

Carlos Estevam era carioca, mas viveu muito tempo em São Paulo, onde construiu sólida carreira acadêmica e política. Talvez por isso tenha aprendido a combinar tão bem o humor, a ironia e o trabalho metódico. Foi daqueles intelectuais de visão abrangente, refinada, avessa a modas, a especializações e a formalidades. Não atuou somente como professor, ainda que sua carreira docente tenha sido brilhante tanto na Universidade de São Paulo (USP) quanto na Universidade Estadual de Campinas (Unicamp). Recusou-se a seguir passivamente os cânones da academia, escapando de suas armadilhas e de sua arrogância. Mergulhou no mundo da gestão e da política, atuando durante anos como diretor de projetos da Fundação do Desenvolvimento Administrativo (Fundap) e sendo Secretário de Estado da Educação por duas vezes, na primeira metade da década de 1990, durante os governos do Partido do Movimento Democrático Brasileiro (PMDB). Na juventude, trabalhou no Instituto Superior de Estudos Brasileiros (Iseb) e foi um dos fundadores, o primeiro diretor e o redator do manifesto do Centro Popular de Cultura (CPC), da União Nacional dos Estudantes (UNE), criado em 1962. Ali, ao lado de Vianinha, Leon Hirszman e Ferreira Gullar, entre outros, experimentou os caminhos da arte popular. De-
\end{abstract}

DADOS - Revista de Ciências Sociais, Rio de Janeiro, Vol. 52, no4, 2009, pp. 821 a 834. 
pois do golpe de 1964 e do fechamento do CPC, mudou-se para a capital paulista e participou da formação do Centro Brasileiro de Análise e Planejamento (Cebrap) em 1969, juntamente com Fernando Henrique Cardoso, Francisco Weffort, José Arthur Giannotti e Francisco de Oliveira, entre outros.

Sua figura inquieta, criativa, que mobilizava colaboradores, exigia atenção e buscava a fórmula lógica perfeita, acompanhou todo um largo e importante trecho da história brasileira recente. Um bom meio de homenageá-lo é tratando-o como o homem de ideias que sempre foi. Isso significa indagar sobre o intelectual nos tempos atuais.

\section{QUESTÕES DILEMÁTICAS}

Falar do intelectual sempre cativa os que apreciam a reflexão política e filosófica, as polêmicas apaixonadas e os embates críticos. Trata-se de um tema clássico, que ocupa lugar de destaque na realidade política e cultural de qualquer época ou país. Passam as modas, mas seu fascínio permanece inabalável: povoou a imaginação dos antigos e não sai do foco dos modernos.

Questões dilemáticas poderiam ser enfileiradas. O intelectual é um humanista ou um técnico, um ideólogo ou um especialista? Pode-se defini-lo como alguém que trabalha com ideias e símbolos ou é preciso ir mais além, buscar seu estatuto vis-à-vis os desafios e as determinações da civilização realmente existente? Deve ele manter distância do poder - escudado por seus princípios-guia e suas verdades - ou pôr-se a serviço das ações governamentais, municiando-as de conhecimentosmeio? Não há como impedir que o intelectual seja envolvido pelos dilemas éticos de seu tempo e por aquela tensão que Max Weber expressou na conhecida fórmula "ética da convicção e ética da responsabilidade". Sendo assim, deve ele ficar com a verdade do conhecimento ou com os fatos do poder, com as convicções ou com as responsabilidades, com as dúvidas "pessimistas" da razão crítica ou com as certezas quase sempre "otimistas" da vontade política? Deve romper com as exigências específicas da gestão e do governo ou abandonar a condição mesma de intelectual? Como não são poucos os intelectuais que interagem ativamente com o poder político - seja ele o do Estado, seja o do partido ou o da universidade -, esse é um tema candente, que costuma dividir opiniões e empolgar. 
A questão do intelectual entrou em nova fase nos últimos tempos (Nogueira, 2004). Antes de tudo, porque nossa época assiste à consolidação e à radicalização daquele "desencantamento do mundo" de que falava Weber no início do século XX. Protagonizamos uma era de especialização, racionalização e profissionalização intensas, em que estão sendo roubadas as bases que fomentavam a reprodução de uma imagem de intelectual - o ensaísta rebelde, que não se submete a rotinas institucionais, não aceita as divisões rígidas do trabalho e está sempre mergulhado em embates doutrinários. É uma era que reduziu dramaticamente a possibilidade objetiva de que se empreendam esforços teóricos totalizantes. No lugar do romantismo revolucionário, dos conflitos éticos e da paixão cívica (e mesmo, se se quiser, dos dilemas existenciais), entraram em cena o cálculo criterioso, as carreiras bem planejadas, o pragmatismo institucional, o respeito aos cânones e aos ritos burocráticos. Isso, diria Weber (1969:1074), equivale a "despojar o mundo de magia" e a aceitar sempre mais a técnica e a previsão: a vida parece fluir como em uma "máquina inerte", moldura de "espíritos coagulados". Nesse contexto, impregnado de saber especializado, como continuar alçando-se ao "universal", à crítica abrangente dos sistemas, à proposição de novos desenhos de vida?

A nossa também se tornou uma era de instituições e de organizações, situação que reflete o estágio de complexidade social em que nos encontramos. Em boa medida, as instituições tendem a chamar para si as tarefas "pedagógicas" que antes cabiam aos intelectuais. Os intelectuais são sempre mais "coletivos" e suas atividades estão cada vez mais condicionadas por orientações políticas que se confundem com iniciativas organizacionais, com seus invólucros administrativos, seus arranjos e suas restrições. A sombra da burocracia agigantou-se. Cresceu o atrito entre a liberdade intelectual e a rotina institucionalizada: a quem servimos hoje, em nome de quem falamos, para quem trabalhamos?

Há ainda os efeitos da informatização e da informacionalização. Ànossa frente, ergue-se um complexo e fragmentado sistema de comunicação, com suas inúmeras redes de contato, suas imagens e informações que explodem sem cessar, suas sempre novas tecnologias da inteligência, que no mínimo subvertem os modos "normais" de produzir e transmitir conhecimentos. Como devem os intelectuais reagir a esse contexto, que os ameaça no âmago e os força à transformação? Os intelectuais sempre foram peças-chave dos processos de construção e re- 
produção de hegemonias. Hoje, nos contextos globalizados, com suas redes sociais conectadas em tempo real por dispositivos comunicacionais que operam como artífices de imaginários, fantasias e "vontades coletivas", a hegemonia já não flui como antes. Do mesmo modo, o intelectual sempre deteve certo tipo de monopólio, o de trabalhar com a palavra, e hoje, nas sociedades da informação, todos trabalham com a palavra e exercem "funções intelectuais". Estreita-se a especificidade do intelectual e muda seu papel social.

Por fim, nossa era está se estruturando sob o emblema da crise, particularmente da crise da política. Os ambientes em que vivemos parecem "despolitizados", vazios de perspectiva cívica, com reduzida noção do que é público. Nada dá muito sentido e expressão às comunidades em que nos inserimos e que nos orientam. Das organizações profissionais à comunidade política "nacional" o clima é de mal-estar, de desconforto e de melancolia. Assistimos a uma complicada alteração nas formas mesmas com que cada um pensa sua relação com o todo: com os demais, com o Estado, com a história, com o futuro. O trabalho intelectual não ficaria assim com seu eixo deslocado, não perderia também sentido e orientação?

Carlos Estevam Martins viveu plenamente a maturação e o cruzamento desses processos. Aceitou-os como desafios até mesmo no plano pessoal mais imediato: jamais utilizou computador. Escrevia intensamente, quase sempre à mão. Trouxe consigo um estilo que vinha dos "heroicos" anos 1950 e 1960, e não fez muita questão de atualizá-lo.

Foi acima de tudo um polemista, dedicado a cobrar coerência de seus interlocutores, a provocá-los com perguntas incômodas, a forçá-los a uma mais rigorosa explicitação de argumentos. Empenhou-se para deixar claras as razões dos distintos campos ideológicos e enfoques, com o objetivo de fazer com que o diálogo fluísse com maior transparência e intensidade. Operou sempre como intelectual público, preocupado em fornecer argumentos acessíveis a todos sobre questões que diziam respeito à vida comum, à coletividade e ao Estado. Viveu debruçado sobre os fatos cotidianos da política e da cultura, pronto para abordá-los em termos polêmicos, com o intuito de demarcar espaços e de educar. Seguiu à risca uma espécie de código ético de sua geração: ser intelectual era agir para esclarecer e persuadir, fazendo vibrar a força das ideias, da razão e dos bons argumentos. 
Carlos Estevam não foi propriamente um estilista. Escrevia muito bem, mas sem afetação. Sua maior virtude foi a posse de uma clareza e de um didatismo que jamais cederam à simplificação. Buscou obstinadamente adotar aquele critério que distingue um escritor público: as ideias claras, expostas de modo limpo e ordenado. Seus textos são encadeamentos lógico-analíticos entremeados de paixão cívica e de empenho compreensivo. Em particular naquele domínio de conhecimento a que mais se dedicou, procurou seguir uma conhecida lição dos clássicos: tratar a política como momento de uma totalidade que é histórica, que se põe e se repõe permanentemente, e por isso mesmo não pode ser compreendida por nenhum pensamento rigidamente especializado, dogmático ou formalista.

Escrevia para ser lido por todos, e não somente por pares e iniciados. Publicou dezenas de ensaios sobre história das ideias, política externa brasileira, redemocratização, sistema político, Estado e capitalismo no Brasil. Alguns de seus livros são preciosos, como A Tecnocracia na História (1975), Capitalismo de Estado e Modelo Político no Brasil (1977), O Circuito do Poder (1994). Vários de seus artigos fornecem, ainda hoje, material para reflexão, conhecimentos agregados e informações, como é o caso de "A Evolução da Política Externa Brasileira na Década 64/74" (Estudos Cebrap, 1975), "Da Globalização da Economia à Falência da Democracia" (Economia e Sociedade, 1996) e "Liberalismo: O Direito e o Avesso" (DADOS, 2003).

Carlos Estevam rejeitou a torre de marfim da especialização e dos princípios abstratos sem se converter em operador tecnopolítico rotineiro. Como intelectual público, esteve próximo daquela figura que o marxista italiano Antonio Gramsci tornou famosa: ser um agente de atividades gerais que é portador de conhecimentos específicos, um especialista que também é político e que sabe não só superar a divisão intelectual do trabalho como também combinar "o pessimismo da inteligência e o otimismo da vontade" (Gramsci, 2000). Ave rara.

A polêmica foi sua marca registrada, impulsionada por uma inventividade exuberante. Dois episódios merecem ser aqui recordados, porque ilustram com clareza seu modo de ser intelectual.

Quando, em 1977, publicou Capitalismo de Estado e Modelo Político no Brasil, a discussão foi intensa. Era um livro audacioso, que trabalhava com o conceito de "burguesia de Estado" para compreender as novas configurações do empresariado brasileiro e seu posicionamento dian- 
te da ditadura militar. Choveram aplausos e questionamentos. Passado o primeiro temporal, Carlos Estevam escreveu um artigo em resposta às críticas, "A Democratização como Problemática Pós-Liberal", publicado pelo Cebrap naquele mesmo ano. Queria ampliar a discussão, explicitar as "alegrias e dores de cabeça" trazidas pelo livro. Elaborou um texto sintomático de seu estilo, saudando os "intelectuais capazes de dar o devido valor ao debate das ideias; audazes trapezistas dispostos a passar por cima das divergências de opinião, que sempre existem, para ir buscar a compreensão empática do ponto de vista alheio" (1977:133) Nele, declarava sua disposição de dialogar com a sociedade: "[...] os mandarins são misantropos. Comunicam-se com o público em geral, impessoalizado, ou com os discípulos, distanciados pela diferença que separa o saber do não saber. Jamais com o próximo" (ibidem).

Foi uma oportunidade de ouro para que se clareassem posicionamentos e estilos: "Nunca consigo fugir à tentação de imaginar que há outros fatos além dos dados disponíveis, assim como não resisto à propensão de supor que qualquer teorização pode ser refeita por meio de mudanças de ênfase, graças à introdução de novos elementos conceituais até então não incluídos na estrutura do marco teórico" (ibidem). Não duvidava do valor e da utilidade das pesquisas empíricas, mas não admitia que seus resultados pudessem resolver questões e pendências que se alojavam em outras dimensões da vida real. Para Carlos Estevam, o mais importante era interrogar o "presente como fluxo", buscando as oportunidades, promessas e "ameaças que encerra para o futuro dos diferentes grupos e classes sociais" (1977:136).

O rigor com palavras e conceitos foi outra de suas preocupações. Em uma das últimas intervenções, no artigo "Vinte Anos de Democracia?", publicado pela revista Lua Nova, manifestou sua perplexidade "face ao que se diz e ao que se prega a respeito de democracia, cidadania e temas conexos" (2005:13). A situação derivada da hegemonia neoliberal e da emergência de uma "nova esquerda romântica" degradara o vocabulário. Em tempos de despolitização, tudo tenderia à diluição. "Nova esquerda" e direita neoliberal se confundiriam sempre mais e estabeleceriam "relações homólogas" (isto é, de equivalência, ainda que não de identidade), que ajudariam a esvaziar a política de critérios razoáveis de embate e compreensão. A questão passaria a ser a defesa da "sociedade contra o Estado e os partidos políticos", como 
se existisse um "Partido Único da Sociedade Civil" que dispensaria tudo o que está institucionalizado (ibidem:27).

Daí a "maldição" lançada contra conceitos e valores essenciais para a democracia: Estado, burocracia, nação, partidos políticos, representação. No lugar deles, formando uma espécie de língua universal, um léxico estruturado pela dupla mercado e sociedade civil. Como então esperar que a democratização se desenvolva "numa sociedade em que a opinião pública [...] é levada a hostilizar [...] toda uma série de elementos ideais, quadros institucionais e mecanismos operacionais" (ibidem:29) sem os quais a democracia não pode funcionar?

Carlos Estevam viveu no centro dessa situação que, bem ponderadas as coisas, tipifica a sociedade brasileira dos últimos quinze anos, ou seja, precisamente o período que assiste ao entrelaçamento dos processos mencionados: desencantamento do mundo, vida organizacional intensiva, informatização, fragmentação social e despolitização. $\mathrm{O}$ neoliberalismo horrorizava-o porque transformava em virtude um cenário de perda da comunidade política, de egoísmo e de desinteresse cívico, de crescimento econômico sem trégua e sem igualdade. À sua maneira, procurou combatê-lo em nome da democracia política e do socialismo democrático. Sua militância intelectual tardia consubstanciou-se em boa medida em torno disso.

É o que transparece com força no artigo "Liberalismo: O Direito e o Avesso", publicado na DADOS em 2003. Escreveu então:

A hegemonia liberal manifesta-se de diversas maneiras. Uma delas consiste no fato de que, hoje em dia, tentar ser antiliberal tornou-se tarefa difícil e até mesmo perigosa, capaz de pôr em risco sólidas reputações. Quem não é ou não quer ser liberal, quem tenta combater o liberalismo em nome de alguma concepção alternativa, enfrenta um terreno minado, repleto de armadilhas que induzem ao erro ou expõem os incautos a críticas imerecidas (2003:619).

A maré montante do neoliberalismo estava impondo um novo credo, um pensamento único, que fazia com que se concluísse que "liberalismo e democracia são a mesma coisa ou coisas que se misturam e se confundem, como na expressão 'regime liberal-democrático'" (idem, ibidem). Pensada como extensão automática do liberalismo, a democracia perderia sua especificidade: dissolver-se-ia na expressão "liberal-democracia" e seria "a tal ponto absorvida pelo termo vizinho que, não 
fosse por sua utilidade para as táticas liberais, poderia ser eliminada sem que de sua exclusão resultasse qualquer prejuízo conceitual" (ibidem:620). Não se tratava, porém, de um problema conceitual, mas sim de uma operação hegemônica: "Nas lutas ideológicas, a indefinição oferece muitas vantagens. Uma delas é ofuscar a visão dos outros" (ibidem). A polissemia posta em curso pelos neoliberais ocultava os defeitos da doutrina e exibia qualidades que ela não possuía. O próprio liberalismo torna-se um termo confuso e empregado para confundir. A conclusão de Carlos Estevam era categórica:

Moral da história: quem não é capaz de definir seu adversário não se livra de ser ludibriado e engolido por ele. Quem não distingue, diferencia, delimita, define e demarca não sabe a que se ater e se desnorteia; mesmo que lute, luta a esmo, sem saber contra o que deve lutar, que alianças mobilizar, que compromissos evitar. As questões terminológicas, ao contrário do que se costuma pensar nos meios políticos, nem sempre se reduzem a meras filigranas acadêmicas (ibidem).

\section{BATALHAS POR HEGEMONIA}

Como todos os intelectuais públicos, Carlos Estevam viveu acossado por múltiplos dilemas, papéis e desafios. Teve de arcar com demandas dirigidas pelo mundo social, pelo mundo cultural e pelos diversos ambientes sistêmicos em que interagiu. Buscou, creio que com sucesso, escapar dos dois tipos extremos que coexistem em nossa era: o intelectual-positivo, produtor de normas e de racionalizações, "colonizador" inconsciente do mundo da vida, e o intelectual "ideológico" e engajado, agitador de ideias e de princípios éticos, mas despojado da perspectiva de incidir positivamente na realidade efetiva. Flutuou entre esses tipos e procurou superá-los, tendo como norte a perspectiva de que intelectuais existem para projetar o futuro, esclarecer, educar, agitar ideias e valores, totalizar e também - last but not least - organizar. Ou seja, vivem em meio a batalhas por hegemonia e poder ideológico.

O poder ideológico tem como principal instrumento a palavra, ou melhor, a expressão de ideias através da palavra. Hoje, a palavra não nos chega mais por meio de contatos "quentes" (o sermão, o comício, a relação pessoal), mas por meio de contatos "frios": a mídia, com suas centenas de jornais, opúsculos, livros, conferências e debates mais ou menos espetaculares e sempre impessoais, além de inumeráveis programas de rádio e TV. Continua-se buscando influenciar comporta- 
mentos, mas agora não só por meio do discurso. O mundo das comunicações de massa é bem mais complexo e não se contenta com palavras: exige sempre mais sons e imagens. Não se contenta também com indivíduos-receptadores ingênuos demais. Os caminhos da reificação se complicaram.

Expandiu-se o campo de atuação dos intelectuais, seja porque cresceram as oportunidades de obter audiência, seja porque se expandiu a produção de conhecimentos, seja porque aumentaram os meios de difusão de ideias. Os intelectuais certamente não ficaram mais poderosos nem estão mais influentes, mas sem eles os sistemas não funcionam e a contestação não se viabiliza. Quanto mais se expandem os meios de informação e comunicação, mais necessários e visíveis ficam os intelectuais. Será isso um indício de que, estando simultaneamente em tantos lugares, os intelectuais talvez já não saibam mais onde devem de fato estar? Será um indício de que, tendo de responder a tantas demandas tópicas e especializadas, os intelectuais já não têm mais como se ocupar daquilo que os tipifica como intelectuais: o esforço de totalização?

Os avanços econômicos e tecnológicos, assim como a diferenciação social decorrente da modernização, trouxeram consigo uma espécie de alteração no peso relativo daquelas duas categorias de intelectuais que Bobbio estabeleceu como típicas: os ideólogos e os experts, os que fornecem princípios e os que fornecem conhecimentos técnicos (1997:71-72). Os especialistas proliferam aos borbotões, colados à lógica mesma da racionalização instrumental que nos domina. Tendem a empurrar para os bastidores os ideólogos, a estigmatizá-los como dinossauros, sobretudo quando associados a uma perspectiva antissistêmica. Os ideólogos "oficiais" do sistema - que pensam o mercado, o indivíduo liberal, o Estado mínimo - são convertidos em intelectuais de outro tipo: ideólogos que se querem sem ideologia, técnicos em princípios gerais, em "soluções", em normas e em lições moralizantes. Em uma época de decisionismo, de rapidez e de resultados, tende-se a cobrar do intelectual uma mudança de postura: menos ideias e mais conhecimentos, menos opinião e mais interesse, menos valores e mais "objetividade". O pensamento normativo chega a ser quase amaldiçoado.

Contudo, os intelectuais, a rigor, precisam tanto da política quanto os seres vivos necessitam de oxigênio. Só têm como se realizar na política 
e a partir da perspectiva da política. Afinal, política não é sinônimo de poder nem de mundo dos profissionais da política, mas um campo em que se disputam as ideias a respeito do viver coletivo, uma aposta nas possibilidades de construir o social, de planejar o futuro, de tornar virtuosa e justa a convivência entre grupos e pessoas. $\mathrm{O}$ intelectual que não se ponha dessa perspectiva e que se recuse a pensar o todo - que se feche em sua torre de marfim, em sua especialização, em seu corporativismo - se mantém em função subalterna.

Há uma transfiguração se exibindo à luz do dia. Não foi por acaso que Russel Jacoby (1990) falou em "últimos intelectuais". O intelectual que estamos hoje acostumados a ver se confinou na universidade ou nos gabinetes governamentais, é dono de um saber tão especializado que só consegue se comunicar com seus pares, fazendo isso quase sempre por meio de teses de difícil compreensão, escritas em linguagem cifrada e hermética, tida como a quintessência do saber objetivo. É uma figura que não desperta maiores sentimentos de simpatia ou empatia no grande público, que com ele mantém uma relação de estranhamento e de frieza. As pessoas ou o temem, ou se põem diante dele com indiferença. Não o compreendem nem podem admirá-lo. Mesmo quando "radical" e de "esquerda", é um tipo de intelectual despolitizado, que pouco contribui para a vida pública ou para a educação política dos cidadãos.

Para os intelectuais - isto é, para os que fazem da relação com as ideias, as imagens e as palavras sua própria razão de ser como cidadãos e profissionais -, a estrutura do mundo atual é hostil, despojada de significado e repleta de ressignificações, pobre de valores e convicções. Paradoxalmente, é uma situação na qual se faz desesperadamente necessário aquele intelectual vocacionado para atuar como figura pública e ajudar a reunir os pedaços da realidade social e da vida pessoal que a globalização está se encarregando de produzir e de espalhar. É um momento complicado porque política e cultura se tornaram dimensões unidas demais e porque o mundo da cultura digital, das "tecnologias da inteligência", está impondo maiores desafios a todos que desejam fazer algo com as ideias. Nele, tendo por fundo a constituição progressiva de uma sociedade global ainda mal compreendida, flui sem empecilhos a opinião de que se acabaram os contrastes, de que temos de nos "adaptar" ao que está aí, de que há apenas uma única explicação e de que, portanto, já não necessitamos tanto de inquietação crítica. 
Particularmente no Brasil, país em que séculos e épocas se abraçam de modo caótico, estamos postos diante do desafio de recuperar o tempo perdido e tendo de tentar imprimir maior velocidade ao processo de transformação do Estado e da sociedade. Para complicar, caminhamos mais ou menos às cegas, com uma sociedade que fala mil línguas e um Estado travado pela globalização. Afinal, estamos inseridos na desordem mundial produzida por esses tempos de crise, que problematizam precisamente a dimensão dos sujeitos e dos projetos, fazem sangrar precisamente o Estado e a política, reduzem as possibilidades de intervenções maciças conscientes ou idealmente orientadas. Terá chegado a hora em que a humanidade experimentará a sério a ausência de qualquer regulação, o império do espontâneo, do não planejado? A época parece impor o primado do mercado, a mercantilização da vida, a conversão das pessoas - pior ainda, dos grupos - em sujeitos aquisitivos, definidos tão somente pela posse de necessidades econômicas. Poderemos alcançar patamares mais elevados de integração e cooperação, algo que se aproxime daquela unificação efetiva do gênero humano concebida por todas as grandes utopias?

O contexto histórico-universal está marcado pela mudança acelerada, pela proliferação de formas cada vez mais complexas de organização, pela convivência absurda de padrões elevadíssimos de tecnologia, ciência e bem-estar com áreas imensas de miséria e pobreza. Há mundialização e fragmentação, resistências fundamentalistas e buscas de novas identidades. Informações e conhecimentos brotam incessantemente, muitas vezes sem sequer serem assimilados. Nesse contexto, os intelectuais são repostos como protagonistas. Estão chamados a contribuir para dar sentido à complexidade crescente, e não apenas para impulsioná-la, mas para disseminar éticas alternativas e impulsos unificadores, para ajudar o mundo a pensar e a adquirir formas mais avançadas de consciência de si.

A nossa é uma época de paradoxos. Do mesmo modo que assistimos à exacerbação de tendências mesquinhas e desumanizadoras, vemos crescer, pelo outro lado, as manifestações de uma nova etapa civilizatória, mais rica de direitos e de possibilidades. Há espaço para outras opções, ainda que os contextos reais sejam pouco permeáveis à construção de alternativas, particularmente nos campos político e cultural. A fragmentação e a atomização da informação, a manipulação facilitada do senso comum, assim como a inexistência de focos geradores de sentido, dificultam a formação de projetos de hegemonia alternativa. 
Nas concretas condições de hoje, a mudança em direção a uma sociedade melhor dependerá do alcance de uma síntese de condições objetivas, vontade política e conhecimento técnico. Mais ainda do que em outros momentos, é na interseção entre cultura e política que podemos encontrar combustível para impulsionar uma transformação dotada de sentido. Donde o destaque adquirido pela questão do conhecimento científico e da aquisição de novos patamares de saber especializado, eixo de todo um esforço para agregar competências na vida política e na gestão do Estado. Donde a nova relevância do intelectual: sua disposição crítica e sua capacidade de forjar projetos e utopias direcionados para a justiça social e a emancipação de todos. A época o solicita sempre mais. Não faz isso sem contradições e sinais ambíguos, mas pede sua presença: não, porém, como assessor mais ou menos qualificado do poder, não como "administrador", mas sim como dirigente, arquiteto de ideias, difusor de pensamento crítico e de conscientização.

Os intelectuais têm diante de si um vasto conjunto de desafios. Parte da batalha política do novo século estará dedicada a decidir se prevalecerá a polarização ideólogos e experts, humanistas e técnicos ou se caminharemos para uma solução ao estilo de Gramsci, geradora de intelectuais que sabem pensar, fazer e organizar e podem, por isso, se dedicar a repor todo o campo das possibilidades e inventar o futuro.

Justamente porque a época está invadida pelas ciências e pela técnica, e ficou "despojada de magia" (Weber, 1969), precisamos de profissionais especializados que sejam porosos, polivalentes, receptivos às ideias e à vida pública: pessoas capazes de construir e organizar, persuadir sem cessar, fixar parâmetros de sentido para a coletividade. Que saibam, digamos assim, reunir múltiplas formas de racionalidade: a razão técnica, que nos ensina a como fazer coisas, a razão crítica, que nos impele a pensar sobre as coisas, e a razão política, que nos ajuda a conviver, a pensar comunitariamente (Nogueira, 2005).

Carlos Estevam Martins foi um "pessimista da inteligência", mas em momento algum deixou de acreditar que seria possível lutar por um futuro melhor, tarefa para a qual seria imprescindível a presença de uma esquerda "menos subdesenvolvida, que não deixe tanto a desejar". Como escreveu em 2005, nunca teremos "um vigoroso [...] pensamento de esquerda, se cada linha de esquerda não tiver o direito de cumprir o seu dever, qual seja, o de explicitar sua identidade, definir 
seus antagonistas, cultivar sua tradição e criticar e atualizar sua trajetória no campo da teoria, assim como no da prática política" (2005:23-24).

Já está fazendo falta.

(Recebido para publicação em dezembro de 2009)

\section{REFERÊNCIAS BIBLIOGRÁFICAS}

BOBBIO, Norberto. (1997), Os Intelectuais e o Poder: Dúvidas e Opções dos Homens de Cultura na Sociedade Contemporânea. São Paulo, Editora Unesp.

GRAMSCI, Antonio. (2000), Cadernos do Cárcere. Volume 2: Os Intelectuais. O Princípio Educativo. Jornalismo. Rio de Janeiro, Civilização Brasileira (edição de Carlos Nelson Coutinho e Luiz Sérgio Henriques).

JACOBY, Russell. (1990), Os Últimos Intelectuais. A Cultura Americana na Era da Academia. São Paulo, Trajetória Cultural/Edusp (tradução de Magda Lopes).

MARTINS, Carlos Estevam. (1977), “A Democratização como Problemática Pós-Liberal”. Estudos Cebrap, no 20, pp. 133-153.

__ (2003), “Liberalismo: O Direito e o Avesso". DADOS, vol. 46, no 4, pp. 619-660.

. (2005), "Vinte Anos de Democracia?". Lua Nova, no 64, pp. 13-37.

NOGUEIRA, Marco Aurélio. (2004). "Os Intelectuais, a Política e a Vida”, in D. de Moraes (org.), Combates e Utopias. Os Intelectuais num Mundo em Crise. Rio de Janeiro, Record.

. (2005). Um Estado para a Sociedade Civil. Temas Éticos e Políticos da Gestão Democrática (2a ed.). São Paulo, Editora Cortez.

WEBER, Max. (1969). Economia y Sociedad. México, Fondo de Cultura Económica. 


\section{ABSTRACT \\ The Public Intellectual's Challenges and Mission}

This article aims to pay tribute to the social scientist Carlos Estevam Martins by reflecting on the figure of the intellectual in the contemporary world. The premise is that a transfiguration is taking place, reinforcing the trend towards overspecialization that hinders intellectuals from engaging in civic ideas and passion. Paradoxically, however, this same transfiguration requires the intellectual's active presence as a character capable of producing meanings and totalizations, and thereby collaborating with the political community to discover more advanced forms of self-awareness.

Key words: public intellectual; political community; Carlos Estevam Martins; overspecialization

\section{RÉSUMÉ}

Défis et Mission de l'Intellectuel Public

Dans cet article qui se propose de rendre hommage à Carlos Estevam Martins, chercheur en sciences sociales, on examine le rôle de l'intellectuel dans le monde actuel. On part du présupposé qu'on assiste à une métamorphose, due à la forte tendance à l'hyperspécialisation, qui éloigne les intellectuels du vrai débat sur les idées et l'intérêt civique. Paradoxalement, cette même métamorphose exige la présence active de l'intellectuel en tant que personnage apte à produire du sens et des synthèses, pouvant ainsi aider la communauté politique à trouver des formes plus évoluées de conscience de soi.

Mots-clé: intellectuel public; communauté politique; Carlos Estevam Martins; hyperspécialisation 